\title{
Flowering, Fertility, and Fruit Production in an Intersubgeneric Alnus Hybrid
}

\author{
Frank S. Santamour, Jr. ${ }^{1}$ \\ U.S. National Arboretum, Agricultural Research Service, U.S. Department of \\ Agriculture, 3501 New York Avenue, Northeast, Washington, DC 20002
}

Additional index words. alder, breeding, inheritance

Interspecific hybrids between taxa that vary significantly in the season of flowering and/or flower bud formation may flower at times that preclude the development of viable seed or render the plants virtually fruitless. While the lack of fruit or seed production was not a desirable outcome of such hybridizations in Ulmus (Santamour, 1989) or Ilex (Santamour and Eisenbeiss, 1991), our program has endeavored to develop new types of alders (Alnus) for landscape planting. The hard, woody female catkins of alders may persist on the trees over winter, or even longer, and when abundant, they can appear messy. Furthermore when the catkins finally fall, they may constitute a litter problem on lawns or sidewalks.

The $\approx 30$ species of the genus Alnus can be classified into distinct subgenera on the bases of seasonal timing of catkin production and flowering (Furlow, 1979). Most of the temperate-zone, tree-type alders [e.g., A. glutinosa (L.) Gaertn.] belong to subg. Alnus and produce staminate and pistillate catkins during the latter part of the growing season, before anthesis. Species of subg. Alnobetula (Ehrhart) Patermann are mostly shrubby (e.g., A.pendula Maxim.), and although they develop staminate catkins in the season before flowering, the pistillate catkins are formed on new shoots that emerge during the flowering season. I wanted to determine when hybrids between species belonging to these two subgenera would initiate staminate and pistillate catkins and if

Received for publication 23 Jan. 1995. Accepted for publication 18 July 1995 . The cost of publishing this paper was defrayed in part by the payment of page charges. Under postal regulations, this paper therefore must be hereby marked advertisement solely to indicate this fact.

${ }^{1}$ Research Geneticist. such hybrids might exhibit physiological abnormalities that would render them fruitless.

In 1985 , we pollinated $A$. pendula (NA 31689 ), from $\approx 35^{\circ} \mathrm{N}$ lat. in Japan, with pollen from trees of three European provenances of A. glutinosa. Catkin-bearing branches of $A$. glutinosa were collected from flowering trees in the test plots of K.C. Steiner (Pennsylvania State Univ.) and forced in the greenhouse. The origins of these trees were given by Maynard and Hall (1981) as Acc. 592 (Hungary, lat. $46^{\circ} 55^{\prime} \mathrm{N}$ ), Acc. 511 (Poland, lat. 53 ${ }^{\circ} 8^{\prime} \mathrm{N}$ ), and Acc. 221 (Denmark, lat. $56^{\circ} \mathrm{N}$ ). Although some apomictic seedlings of $A$. pendula were present in all seedling progenies, true hybrids were produced by all three $A$. glutinosa parents and were easily distinguished by the few leaf veins and lower leaf length : width ratio. Furlow (1979) stated that "although several species of (subg.) Alnus and (subg.) Alnobetula grow sympatrically, they do not produce hybrid offspring." Before this work, only one controlpollinated intersubgeneric hybrid combination had been reported in the literature. This was a cross between $A$. sieboldiana Matsum. and $A$. hirsuta var. tinctoria (Sarg.) Kudo made by Murai in Japan in 1963. Murai (1964) designated this hybrid as A. ×moriokaensis and noted that it was a "bad combination" with "small growth."

Fifty-one hybrid seedlings were established in field test plots in 1987 and 1988. The hybrids were decidedly shrubby, like $A$. pendula, with multiple trunks. Flowering began in 1990, and in 1991 and 1992, I made systematic observations on the parents and on plants of each of the three hybrid progenies. On 28 Aug. 1991, female catkins were just beginning to emerge on the hybrids and the male catkins were between 10 and $20 \mathrm{~mm}$ long. By 20 Nov. 1991, the terminal male catkins on the hybrids were $\approx 34 \mathrm{~mm}$ long and two to three female catkin clusters had developed from lateral buds below the terminal. Male catkins of A. glutinosa were $\approx 48 \mathrm{~mm}$ long and from three to five lateral clusters of female catkins were noted. The male catkins of $A$. pendula averaged $34 \mathrm{~mm}$ long.

Anthesis of male catkins of A. glutinosa took place about $28 \mathrm{Feb}$. 1992, at which time the catkins were 67 to $80 \mathrm{~mm}$ long. Elongation of the male catkins on the hybrids was just beginning on 17 Mar. 1992, but elongation in A. pendula did not start until 30 Mar. 1992. With A. glutinosa, $96 \%$ of pollen was stainable with aceto-carmine and the grains averaged $25.1 \mu \mathrm{m}$ in diameter and most had five germinal apertures. Only $1 \%$ of pollen of $A$. pendula was not stainable, with the 4- to 5colpate grains averaging $22.5 \mu \mathrm{m}$ in diameter. Male catkins of the hybrids, brought into the laboratory on 24 Mar. 1992, elongated to 55 to $95 \mathrm{~mm}$, but the anthers did not dehisce and there was no staining of expressed pollen. This high rate of pollen abortion might have been caused by freezing weather for six consecutive days after catkin elongation had begun in the field. However, trials in 1993, in the absence of freezing temperatures, also indicated complete pollen abortion in the hybrids. Parthenocarpic fruit developed on the hybrids and persisted for more than 1 year. No viable seed was produced. The parent trees of both species were found to have $2 n=28$ chromosomes, which, based on $x=7$, is a tetraploid number.

In summary, intersubgeneric hybrids between A. glutinosa and A. pendula produced both female and male catkins in the season before flowering (like A. glutinosa), and although the hybrids were virtually sterile, parthenocarpic and persistent fruit were produced.

\section{Literature Cited}

Furlow, J.J. 1979. The systematics of the American species of Alnus (Betulaceae). Rhodora 81:1$121,151-248$

Maynard, C.A. and R.B. Hall. 1981. Early results of a range-wide provenance trial of Alnus glutinosa (L.) Gaertn. Proc. Northeastern For. Tree Improv. Conf. 27:184-201 (1980)

Murai, S. 1964. Phytotaxonomical and geobotanical studies on gen. Alnus in Japan. III. Taxonomy of whole world species and distribution of each sect. Bul. Govt. For. Expt. Sta. (Tokyo) 171.

Santamour, F.S., Jr. 1989. Flowering and fertility of hybrids between spring- and fall-flowering elms. HortScience 24:139-140.

Santamour, F.S., Jr., and G.K. Eisenbeiss. 1991. Flowering and fertility in "English" $x$ "American" holly hybrids. Holly Soc. J. 9(3):3-6. 